\title{
Mathematical Statistics Method of Evaluating Application Effects of a New Type of Gas Anchor
}

\author{
Jun Wang1, Wen-He Li'2 ${ }^{2}$ Rong Zhong3 \\ ${ }^{1}$ Enhanced Oil and Gas Recovery Key Laboratory of Ministry of Education, Northeast Petroleum University, \\ Daqing, China \\ ${ }^{2}$ College of Mathematics and Statistics, Northeast Petroleum University, Daqing, China \\ ${ }^{3}$ The First Production Plant, Daqing Oilfield Co. Ltd., Daqing, China \\ Email: 84541941@qq.com
}

Received 1 July 2015; accepted 20 July 2015; published 23 July 2015

Copyright (C) 2015 by authors and Scientific Research Publishing Inc.

This work is licensed under the Creative Commons Attribution International License (CC BY).

http://creativecommons.org/licenses/by/4.0/

(c) (i) Open Access

\begin{abstract}
Based on the basic formula of the confidence interval and the sampling error of mathematical statistics, the mathematical statistics method of evaluating application effects of a new type of gas anchor was given in this paper. By the method mentioned above, the confidence interval and the sampling errors of the relevant mean value differences of Daqing Oilfield $S$ block's 150 wells, according to the mean value differences of the liquid producing capacity per day, the oil production per day, the submergence depth of the 10 sampling test wells, in which before and after a new type of gas anchor were laid down, were calculated. The calculation results show that a new type of gas anchor has a better effect of increasing oil production of oil well and enhancing pump efficiency. Through the real value differences analysis of the liquid producing capacity per day, the oil production per day, the submergence depth of 150 wells mentioned above, in which before and after a new type of gas anchor were laid down, it was verified. By using the confidence interval and the sampling errors of the liquid producing capacity per day, the oil production per day, the submergence depth mentioned above, in which before and after a new type of gas anchor were laid down, the application effects of a new type of gas anchor could be evaluated. And a mathematical statistics method of evaluation application effects of a new type of gas anchor is presented.
\end{abstract}

\section{Keywords}

A New Type of Gas Anchor, Confidence Interval, Sampling Error, Application Effects Evaluation 


\section{Introduction}

A new type of gas anchor has been more and more widely used in Daqing Oilfield, and its application effect evaluation is not only big workload, but also relating to its promotion prospects [1] [2]. So, it has important engineering significance to provide a low consumption and high efficiency method to evaluate a new type of gas anchor. The basic formula of the confidence interval and the sampling error of mathematical statistics will be given in this paper [3]. Based on the basic formula mentioned above, a mathematical statistics method of evaluating application effects of a new type of gas anchor will be provided, and the method mentioned above will be used for the evaluation of application effects of a new type of gas anchor of Daqing Oilfield S block.

\section{Method}

\subsection{The Basic Formula}

Assume that the sample $x_{1}, \cdots, x_{n}$ is from the population $N\left(\mu_{1}, \sigma_{1}^{2}\right)$, which before a new type of gas anchor were laid down, and the sample $y_{1}, \cdots, y_{n}$ is from the population $N\left(\mu_{2}, \sigma_{2}^{2}\right)$, which after a new type of gas anchor were laid down. Two samples are mutual independence, $\bar{x}$ and $\bar{y}$ are the sample mean values of them respectively.

Assume that $\sigma_{1}^{2}=\sigma_{2}^{2}$, and right now, the confidence interval of $\mu_{1}-\mu_{2}$, which the confidence level is $1-\alpha$ is [4]:

$$
\left[\bar{x}-\bar{y}-t_{\alpha / 2}(m+n-2) S_{w} \sqrt{\frac{1}{m}+\frac{1}{n}}, \bar{x}-\bar{y}+t_{\alpha / 2}(m+n-2) S_{w} \sqrt{\frac{1}{m}+\frac{1}{n}}\right]
$$

Here:

$$
S_{w}=\sqrt{S_{w}^{2}}=\sqrt{\frac{(m-1) S_{x}^{2}+(n-1) S_{y}^{2}}{m+n-2}}
$$

The sampling error:

$$
\Delta x=t_{\alpha / 2}(m+n-2) S_{w} \sqrt{\frac{1}{m}+\frac{1}{n}}
$$

The sample mean values:

$$
\begin{aligned}
& \bar{x}=\frac{1}{m} \sum_{i=1}^{m} x_{i} \\
& \bar{y}=\frac{1}{n} \sum_{i=1}^{n} y_{i}
\end{aligned}
$$

The sample standard deviations:

$$
\begin{gathered}
S_{x}=\sqrt{S_{x}^{2}}=\sqrt{\frac{1}{m-1} \sum_{i=1}^{m}\left(x_{i}-\bar{x}\right)^{2}} \\
S_{y}=\sqrt{S_{y}^{2}}=\sqrt{\frac{1}{n-1} \sum_{i=1}^{n}\left(y_{i}-\bar{y}\right)^{2}}
\end{gathered}
$$

The sample variances:

$$
\begin{aligned}
& S_{x}^{2}=\frac{1}{m-1} \sum_{i=1}^{m}\left(x_{i}-\bar{x}\right)^{2} \\
& S_{y}^{2}=\frac{1}{n-1} \sum_{i=1}^{n}\left(y_{i}-\bar{y}\right)^{2}
\end{aligned}
$$




\subsection{The Calculation Method}

The sampling error of mean value differences can be calculated with the Formula (1-3),when the confidence level of $1-\alpha$ and the date of the liquid producing capacity per day, the oil production per day, the submergence depth of the oil wells, in which before and after a new type of gas anchor were laid down, are given. and then the relevant confidence interval of mean value differences can be calculated with the Formula (1-1).

(1) Calculate the sample mean values $\bar{x}$ and $\bar{y}$ of the liquid producing capacity per day, the oil production per day and the submergence depth, which before and after a new type of gas anchor were laid down, with the Formulas (1-4) and (1-5); and calculate the sample standard deviations $S_{x}$ and $S_{y}$ of the sampling oil wells, in which before and after a new type of gas anchor were laid down, with the Formulas (1-6) and (1-7); and calculate the sample variance $S_{x}^{2}$ and $S_{y}^{2}$ of the sampling oil wells, in which before and after a new type of gas anchor were laid down, with the Formulas (1-8) and (1-9);

(2) Calculate the value of $t_{\alpha / 2}(m+n-2)$ with the statistical function TINV, when the confidence level $1-\alpha$ and the number $n$ of sample well are given;

(3) Calculate $S_{w}$ with the Formula (1-2), by using to the values of the sample standard deviations;

(4) Calculate the confidence interval of mean value differences of the liquid producing capacity per day, the oil production per day and the submergence depth, when before and after a new type of gas anchor were laid down, with the Formula (1-1) of confidence interval.

\section{Results and Discussion}

According to the basic formula and mathematical statistics method mentioned above and the production data of the oil wells, the confidence intervals and the sampling errors of the relevant mean value differences of Daqing Oilfield S block's 150 wells, with the mean value differences of the liquid producing capacity per day, the oil production per day, the submergence depth of the 10 sampling test wells, in which before and after a new type of gas anchor were laid down, are calculated, when the confidence level of $95.0 \%$ is set. The confidence intervals and the sampling errors are: [-54.1860, -16.5640$]$, [-2.0692, -0.0188$]$, [12.6554, 245.9846]; $\pm 18.8111 \mathrm{t} / \mathrm{d}$, $\pm 1.0252 \mathrm{t} / \mathrm{d}, \pm 116.6646 \mathrm{~m}$, which show that the liquid producing capacity per day increases, the oil production per day increases, the submergence depth reduces. It is indicated that a new type of gas anchor has a better effect for increasing the production of oil well and enhancing the efficiency of pump.

Through the comparisons and analyses of the real measurement data from oil wells, the well numbers of the real value difference of the oil production per day, the oil production per day and the submergence depth, being within the confidence intervals mentioned above, of Daqing Oilfield S block's 150 wells, in which before and after a new type of gas anchor were laid down, are 142,146 and 145 respectively, with all achieving the confidence level of $95.0 \%$,which means that the mathematical statistics method to evaluate the application effects of a new type of gas anchor given by this paper is feasible.

\section{Conclusions}

(1) Based on the basic formula of the confidence interval and the sampling error of mathematical statistics, the mathematical statistics method of evaluating application effects of a new type of gas anchor was given.

(2) According to the method mentioned above, the confidence intervals and the sampling errors of the relevant mean value differences of Daqing Oilfield S block's 150 wells, with the mean value differences of the liquid producing capacity per day, the oil production per day, the submergence depth of the 10 sampling test wells, in which before and after a new type of gas anchor were laid down, were calculated when the confidence level of $95.0 \%$ is set. The calculation results show that the liquid producing capacity per day increases, the oil production per day increases and the submergence depth reduces when after a new type of gas anchor were laid, which means that a new type of gas anchor has a better effect for increasing the production of oil well and enhancing the efficiency of pump.

(3) Through the comparisons and analyses of the real measurement data from oil wells, the well numbers of the real value difference of the oil production per day, the oil production per day and the submergence depth being within the confidence intervals mentioned above of Daqing Oilfield S block's 150 wells in which before and after a new type of gas anchor were laid down are 142, 146 and 145 respectively with all achieving the confidence level of $95.0 \%$, which means that the mathematical statistics method to evaluate the application effects of a new type of gas anchor given by this paper is feasible. 


\section{References}

[1] Wang, Y., Miao, X.-L., Cui, H.-Q., Song, X.-L. and Fu, C. (2007) Analysis of Degassing Efficiency of the Multi Cup Isoflux Hor. Journal of Daqing Petroleum Institute, $\mathbf{3 1}$.

[2] Wang, Y., Fu, C., Cui, H.-Q. and Song, X.-L. (2008) Analysis of Degassing Efficiency of Corrugate Multicup Isoflux Gas Anchor. Ocean Press, Beijing, 555-561.

[3] Xu, B. (2007) Probability and Mathematical Statistics. Zhejiang University Press, Hangzhou.

[4] Bird, K.D. (2008) Analysis of Variance via Confidence Intervals. SAGE Publications Ltd., Thousand Oaks. 